Brit. Heart f., 1969, 31, 163.

\title{
Long-term Transcutaneous Endocardial Pacing in Management of Complete Heart Block
}

\author{
N. CONWAY, J. SEYMOUR, AND D. GIBBONS \\ From the Department of Cardiology, The Middlesex Hospital, Londcn W.1
}

When endocardial pacing is used for the longterm treatment of heart block, the pacemaker unit may either be implanted subcutaneously or, alternatively, left outside the body and connected to electrodes crossing the skin (transcutaneous pacing). Complete implantation of the pacing system is now widely favoured since it appears that this reduces the risks of blood stream infection and of loss of pacing due to movement of the catheter tip (Bluestone et al., 1965). The consequence, however, has been an increase in the problems associated with electronic after-care and pacemaker replacement and the addition of a fresh hazard-sepsis around the implanted unit itself. Therefore, as many early patients at this hospital, paced with external units, had a relatively trouble-free course, we were encouraged to continue this method of pacing as a long-term measure. In this paper our experience of this group is reviewed with particular emphasis on the incidence of infection and the stability of pacing. Relatively few accounts of long-term transcutaneous endocardial pacing have been published (Siddons and Sowton, 1967).

\section{SUBJECTS AND METHODS}

Twenty-five patients ( 18 men, 7 women), aged between 36 and 85 years (mean 69 years), have been treated by long-term transcutaneous endocardial pacing. All had complete heart block which was, however, intermittent in several cases. The indication for long-term pacing was repetitive Adams-Stokes attacks, resistant to medical treatment in 24 instances, and heart failure in 1. Four had had a previous period of epicardial pacing with an implanted pacemaker which had been terminated by infection.

The technique of positioning the endocardial electrode has been described by Bluestone et al. (1965). The following modifications were employed. (a) The exit

Received July 25, 1968. wound in the neck was 2 to $3 \mathrm{~cm}$. placed lateral to the vein entry site so that a short, subcutaneous tunnel separated this point from the skin wound. (b) The indifferent wire was inserted subcutaneously over the sternum. The pacing catheter used was the U.S.C.C. unipolar C 50 (size 5) or, more recently, the Device's "D" catheter. The pacemaker was the Device's fixed rate abdominal unit unless high thresholds were present when the Vitatron external unit was used (since this has adjustable power output).

Dressings are changed every 3-4 weeks at a special clinic, when the wounds are inspected for signs of infection. Both pacing electrodes are coiled on the chest and strapped down throughout their length, the strapping being changed at each visit. To avoid plaster reactions Micropore tape is used. Patients are instructed to avoid wetting the dressings when washing.

The replacement of pacemaker units, when this is necessary, is a minor procedure since another pacemaker is easily connected in parallel with the patient's own unit and control transferred without a break in pacing. Similarly, replacement of an indifferent electrode is simple.

\section{RESULTS}

The mean period of transcutaneous pacing in the 25 patients is 24.9 months (range 3-46 months). Thus our total experience covers 622 patientmonths. Six patients have been paced for more than three years.

Deaths. Seven patients have died. The cause of death was intercurrent disease in four instances (Cases 1, 6, 7, and 8-myocardial infarction, heart failure from valvar disease, carcinoma, gangrene of the leg, respectively). Three patients (Cases 2, 4, and 11) died suddenly, but only in the last was the pacing system known to be functioning correctly: at the time the patient had septicaemia which had responded to antibiotics, but sepsis may have lowered the threshold for ventricular fibrillation. 
The other two patients died at home and their deaths may have been due to a pacing failure.

Stability of Endocardial Catheter. Using the method of pacing described, it might be expected that the catheter tip would be liable to disimpact from its site in the right ventricle because of external traction on the catheter. Sixteen patients never experienced this complication. On 19 occasions (in the other 9 patients) pacing became erratic or stopped because of such an accident. This occurred once with 3 patients, twice with 4 patients, and four

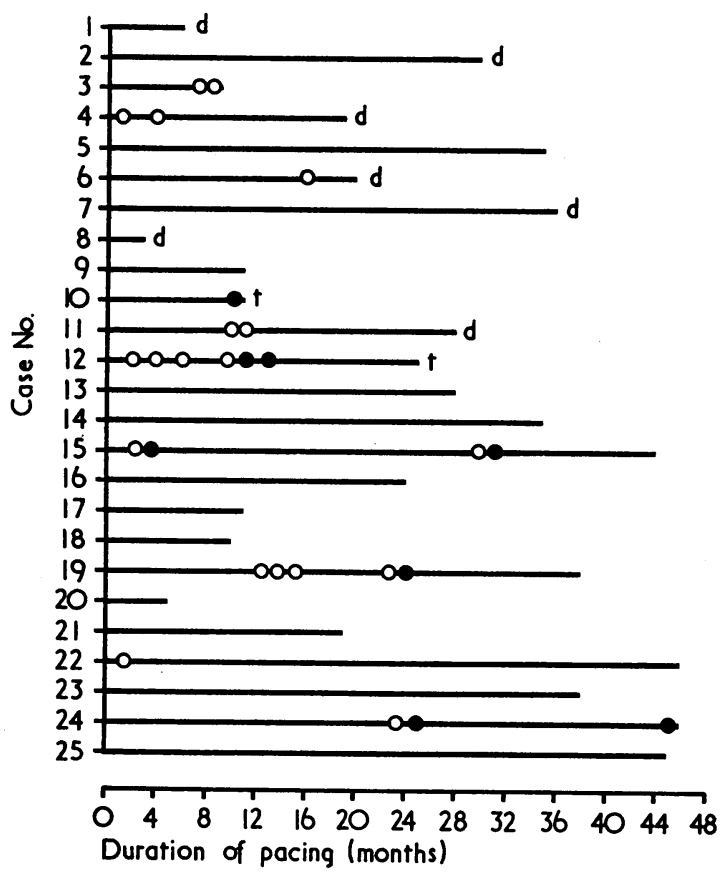

Fig. 1. Stability of electrode catheter. $O$, catheter repositioned; $\bullet$, catheter changed; $d$, patient died; $t$, patient transferred.

times with 2 patients. Twice (in the same patient) the catheter tip had advanced into the pulmonary artery. Twice the tip was pulled back into the right atrium. On all other occasions the catheter tip remained within the right ventricle but required repositioning to restore pacing. In no instance was the ventricle perforated. The dressing procedure caused movement of the catheter tip once only. The consequence of catheter movement was serious in 4 patients only, all of whom had an Adams-Stokes attack. It may have accounted for the two deaths about which no information is available.
The timing of these events is shown in Fig. 1. There was a tendency for repositioning to be required several times in succession in certain patients, and a change of catheter was usually successful in achieving a stable position.

Replacement of the pacing catheter was needed eight times in all (Fig. 1), seven of them for electronic faults-poor electrode position or presumptive catheter insulation breakdown. In one patient (Case 12) the catheter was electively replaced in a different vein because of a troublesome infection at the catheter entry site. Interestingly, he developed septicaemia shortly after this change was carried out. Twenty patients have not required a change of catheter.

The Indifferent Electrode. The indifferent wire has been changed 34 times in 14 patients. Initially, routine replacement was carried out every 6-12 months and this accounts for 24 replacements. On 7 occasions the wire appeared to be poorly secured. On two occasions the wire broke but no serious symptoms resulted. Such a mishap may have accounted for the two unexplained deaths. Only once was the wire removed because of infection. Eleven patients have never had a replacement.

Local Infection. Infection at the site of the indifferent wire occurred 11 times in 5 patients and at the catheter entry site on 19 occasions in 9 patients. Details are shown in Fig. 2. There was no close relation between the incidence of infection and the time of insertion of either electrode or the length of time for which pacing had been in progress. Once infection occurred it tended to recur so that 5 patients account for 23 of the 30 episodes of infection. Fourteen patients have never had any infection at all.

Most of these infections have been minor, consisting merely of trivial inflammation without discharge. Culture isolated Staphylococcus pyogenes on 6 occasions from 3 patients but only once was this organism resistant to penicillin. Other organisms included Staphylococcus albus and diphtheroids. Proteus, Esch. coli, and Klebsiella were isolated in one patient only. The duration of infection was usually short, healing having occurred by the next visit in 23 instances and by the third visit in 5 more. One patient (Case 5) has had a relapsing infection in a small sinus near the catheter entry site for 8 months. The entry wound itself is clean.

Treatment has included antibiotics 14 times, usually tetracycline. On one occasion (Case 12) the pacing catheter was changed because of local infection (see below). 
Septicaemia. Four episodes of septicaemia have occurred in three patients. In no instance was it necessary to remove the catheter. On three occasions the infection was cured. The second episode of septicaemia in Case 11 also responded to antibiotics, but the patient died of ventricular fibrillation during his admission. In each case Staphylococcus pyogenes, sensitive to penicillin, was isolated. Brief case histories follow.

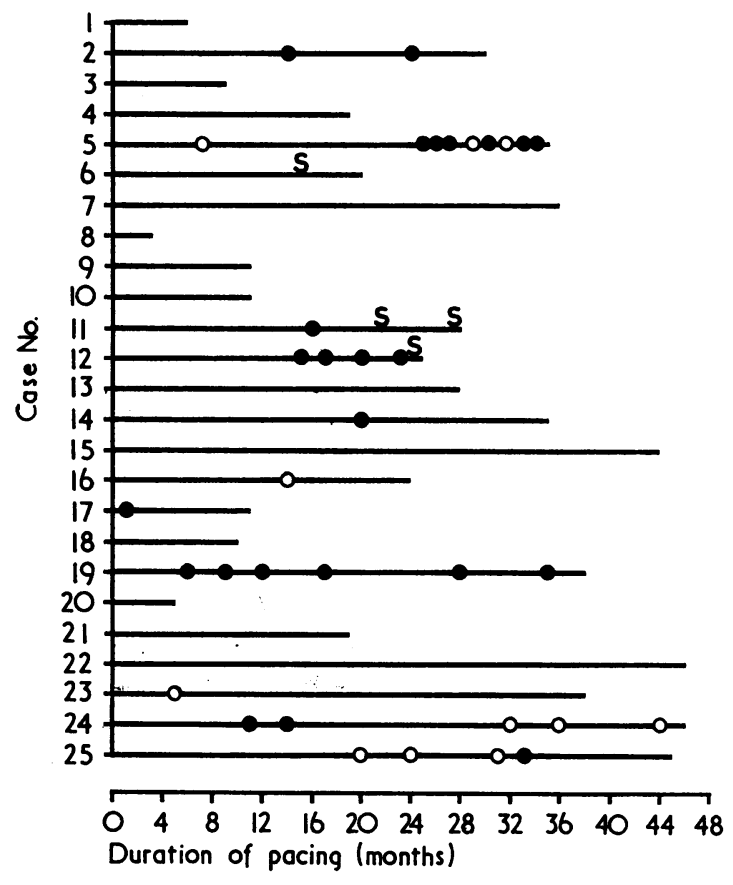

FIG. 2. Incidence of infection. $\bullet$, infection at catheter entry; $O$, infection at site of indifferent wire; $S$, septicaemia.

Case 6. A 58-year-old man with rheumatic aortic incompetence developed complete heart block in December 1963. Septicaemia occurred after uneventful pacing for 14 months. The neck wound was clean. Treatment with penicillin 12 mega units and ampicillin 2 g. daily for 5 weeks cured the infection. A year later he died of heart failure. No evidence of infection was found.

Case 11. A 42-year-old man with complete heart block was paced initially with an epicardial implanted system. This became infected and endocardial pacing was substituted. Septicaemia occurred 21 months later but was cured with penicillin 8 mega units and streptomycin $2 \mathrm{~g}$. daily for 14 days. Eleven months later septicaemia recurred. The same antibiotic regimen produced rapid improvement and fever subsided. Three days after admission he died suddenly. At necropsy the electrodes were not displaced or broken and the pacemaker was functioning normally. No infection of the neck wound was present before either episode of septicaemia.

Case 12. A 65-year-old man was paced endocardially for Adams-Stokes attacks. After 16 months a trivial infection occurred at the catheter entry site. Seven months later the infection recurred and persisted. To eliminate this, the electrode catheter was replaced by a new one in the other jugular vein under antibiotic cover. Both wounds healed well, but 10 days later, septicaemia occurred. Treatment with penicillin 30 mega units and streptomycin $1 \mathrm{~g}$. daily controlled the infection but he developed a sensitivity reaction to penicillin. Final cure was achieved with tetracycline $1 \mathrm{~g}$. and streptomycin $1 \mathrm{~g}$. daily for three weeks.

\section{Discussion}

In long-term endocardial pacing an external pacemaker has certain well-recognized advantages over an implanted one. It is accessible to direct electronic measurement and its power output is readily adjustable. Interference with pacemaker function by sepsis (Sowton, 1968) or the inadvertent entrance of tissue fluid (Trimble, 1965) is avoided. Most important, the replacement of pacemaker units is simple. Sowton (1968), reviewing 278 pacemakers implanted in the British Isles in a 12-month period, noted that pacemaker failure occurred in 41 per cent during this period (or $57 \%$ of all causes of loss of pacing). Whether or not this high proportion was in part the consequence of implantation, it certainly underlines the disadvantages of changing pacemakers if these are buried. Again, should the catheter move, it can be repositioned more easily if it is not implanted, since one is not confined to a restricted loop of catheter, dissected from the neck, for manoeuvring purposes.

Nevertheless, this method of transcutaneous pacing has three principal drawbacks: first, the need for frequent attendances for dressings (which must be kept dry) and the clutter of pacemaker, pouch, wires, and plaster; next, the risk of sepsis; lastly, the increased likelihood of movement of the catheter tip.

The first of these disadvantages is considered by Siddons and Sowton (1967) a major reason favouring implantation, since they state that patients are otherwise all too conscious of their dependence on electronic equipment. Be this as it may, in our experience implantation raises its own psychological difficulties. It is true most patients prefer it at first. Later many of them grow concerned about the difficulties involved in replacement of pacemakers or electrodes and fear repeated operations. Certainly none of our patients has complained about this feature of their management, even those with 
previous experience of an implanted system, whereas at least one patient with a buried unit has asked for it to be changed to an external one.

The second problem is sepsis. Local infection at the catheter entry site has been trivial in most of our patients, only one of whom has had troublesome sepsis. While systemic infection may follow even such minor inflammation, this was not seen in the present series.

Septicaemia is the most serious hazard of transcutaneous endocardial pacing. It occurred four times in three of our patients or about once in every 150 patient-months. It has been described as a risk of repositioning an external electrode (Harris et al., 1965), but we have noted no such association (Fig. 1 and 2). The use of a subcutaneous tunnel between the skin wound and the actual point of venous entry reduces the risk of septicaemia (Lagergren and Johansson, 1963). Implantation of the entire pacing system certainly reduces it further but does not eliminate it. Septicaemia has followed ulceration of the catheter loop through the skin of the neck (Bluestone et al., 1965) and may complicate sepsis around the buried unit.

It has previously been implied that removal of the catheter is necessary if a cure of the septicaemia is to be achieved (Harris et al., 1965; Furman et al., 1966). Naturally, this would seriously complicate management and alternative pacing arrangements would be required. In fact, in several instances (Lagergren and Johansson, 1963; Schwedel and Escher, 1964; Gold, Paneth, and Gibson, 1966) it has proved possible to cure the infection with antibiotics without removal of the catheter or any interruption in pacing and this has been our experience as well. One of our patients, who developed septicaemia in 1963, had valvar heart disease. Nowadays he would not be considered suitable for transcutaneous pacing because of the risk of endocarditis, yet it is noteworthy that he too was cured of infection with the catheter in situ.

The third drawback to long-term endocardial pacing with an external unit is the increased liability of movement of the catheter tip with erratic or interrupted pacing as a result. The present study confirms this tendency. It is probably possible to reduce the risk of this happening by use of a longer subcutaneous tunnel between the veins and the skin (Lagergren and Johansson, 1963). In no instance, to our certain knowledge, did such accidental movement result in death, but Adams-Stokes attacks occurred four times, and there remain two patients whose death may be attributable to such a mishap. This hazard is, to some extent, balanced by the lower incidence of catheter fracture with the transcutaneous method (Bluestone et al., 1965), at least with the particular type of catheter we used and, possibly, by the smaller risk of biological interference with pacemaker function with nonimplanted units.

The mortality of this admittedly small series compares favourably with other published experience $(10-15 \%$ in the first year-Chardack, 1967; Sowton, 1967). Only three deaths (12\%) are attributable to pacing failure over a (mean) period of 24 months. Siddons and Sowton, while recommending implantation of the pacemaker, comment on the relatively trouble-free course of their patients paced by the transcutaneous endocardial system, especially after they adopted the use of a long subcutaneous tunnel to reduce the risk of septicaemia. Our experience suggests that, with this modification (which should also improve catheter stability), the technique we describe is an acceptable method of long-term pacing in suitable patients.

\section{SUMMARY}

Twenty-five patients with complete heart block have been treated by endocardial pacing without implantation of the pacemaker for a mean period of two years (range 3-46 months). Local sepsis caused little trouble, but four episodes of septicaemia occurred (in three patients). In each instance, septicaemia responded to antibiotics with the catheter left in situ and there was no interruption in pacing. Septicaemia may have contributed to the death of one of these patients from ventricular fibrillation. An increased liability of the catheter to move was noted, but this hazard (and the risk of septicaemia) can probably be reduced by the use of a longer subcutaneous tunnel between the skin wound and the site of catheter entry into the vein. Four patients died of intercurrent disease and there were three deaths from complications or failure of pacing - a mortality that compares favourably with other published experience. The merits and drawbacks of this method of pacing are discussed.

We are grateful to Dr. Walter Somerville and Dr. Richard Emanuel for permission to report their patients. We thank Dr. Somerville for much helpful advice and criticism. We wish to thank successive staff nurses in the Cardiac Department for their able assistance.

\section{REFERENCES}

Bluestone, R., Davies, G., Harris, A., Leatham, A., and Siddons, H. (1965). Long-term endocardial pacing for heart-block. Lancet, 2, 307.

Chardack, W. (1967). In Cardiac Pacing and CardioversionSymposium of the American College of Cardiology, p. 60. The Charles Press, Philadelphia. 
Furman, S., Escher, D. J. W., Schwedel, J. B., and Solomon, N. (1966). Transvenous pacing: a seven year review. Amer. Heart F., 71, 408.

Gold, R. G., Paneth, M., and Gibson, R. V. (1966). A new technique for long-term endocardial pacing. Lancet, $1,908$.

Harris, A., Bluestone, R., Busby, E., Davies, G., Leatham, A., Siddons, H., and Sowton, E. (1965). The management of heart block. Brit. Heart f., 27, 469.

Lagergren, H., and Johansson, L. (1963). Intracardiac stimulation for complete heart block. Acta chir. scand., 125, 562.
Schwedel, J. B., and Escher, D. J. W. (1964). Transvenous electrical stimulation of the heart. Ann. N.Y. Acad. Sci., 111, 972.

Siddons, H., and Sowton, E. (1967). Cardiac Pacemakers. Charles C. Thomas, Springfield, Illinois.

Sowton, E. (1967). Cardiac pacemakers and pacing. Mod. Conc. cardiov. Dis., 36, 31.

- (1968). Result of a British survey on artificial cardiac pacemakers. Brit. med. F., 2, 11.

Trimble, A. S. (1965). The implantable cardiac pacemaker: late failures and their management. F. thorac. cardiovasc. Surg., 50, 707. 